\title{
Enquête sur les cultures fruitières dans les exploitations familiales agricoles en zone humide du Cameroun
}

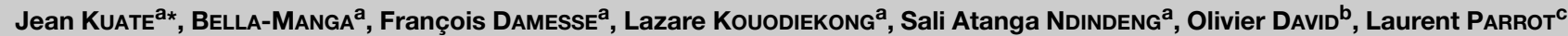

\author{
a Irad Nkolbisson, Programme \\ Fruits, BP 2067, Yaoundé, \\ Cameroun \\ jeankuate@yahoo.fr \\ ${ }^{b}$ Irad / Scac, BP 1616, \\ Yaoundé, Cameroun \\ ${ }^{c}$ Irad / Cirad, BP 2067, \\ Yaoundé, Cameroun
}

\section{Fruit trees cultivated in family farms in the humid zone of Cameroon: a survey.}

Abstract - Introduction. The lack of reliable and exhaustive data on fruit tree farming is a real constraint to the elaboration, as well as impact assessment, of a sound development strategy on fruit production. A survey was conducted on fruit trees in three locations (Bokito, Foréké and Yaoundé) in the humid zone of Cameroon. Materials and methods. Fruit tree farming was characterized by analyzing the producer status and the place of this speculation among the various activities conducted in the household. The various fruit tree species in orchards, number of plants, origin of planting material and age of trees, as well as production constraints were studied for a total of 193 family farms. Results and discussion. The heads of households ( 51 years old on average) are $90 \%$ males and have a relatively low education level. The diversity of fruit tree species varied with location. Orchard composition in terms of species was also variable, but four major species (African plums or Dacryodes edulis, oranges, mangoes and pears) constitute about $78 \%$ of the trees. This distribution globally matches preferences expressed by farmers for these species. Among these trees, young ones $(<10$ years), which indicate a move in recent plantings, constitute on average $(15,21$ and 38)\% in Bokito, Foréké and Yaoundé, respectively. Nevertheless, important discrepancies among species and locations are observed and discussed. In terms of contribution to family food security, fruits ranked 1st, 2nd and 4th, respectively, in Bokito, Foréké and Yaoundé among other activities. Production constraints are from three main sources: phytosanitary (poor management of pests and diseases), agronomic (unimproved seedlings) and socioeconomic (land and input availability). Conclusion. Important data on fruit trees was obtained in the humid zone of Cameroon. The implications of these findings are discussed with the perspective of improving quality, quantity and sustainability of fruit production in the country.

Cameroon / fruit trees / farm surveys / suburban areas / injurious factors

\section{Enquête sur les cultures fruitières dans les exploitations familiales agricoles en zone humide du Cameroun.}

Résumé - Introduction. L'absence de données statistiques fiables et exhaustives sur les exploitations fruitières constitue un handicap pour élaborer une stratégie pertinente de développement de ces cultures et en évaluer l'impact. Une enquête a été réalisée sur les cultures fruitières dans trois sites (Bokito, Foréké et Yaoundé) en zone humide du Cameroun. Matériel et méthodes. Les arbres fruitiers cultivés ont été caractérisés en analysant le profil du producteur et la place de ces cultures dans les activités pratiquées par les familles des exploitants agricoles. Les espèces présentes, le nombre de pieds, l'origine du matériel végétal, l'âge des arbres et les contraintes de production ont été étudiés dans 193 exploitations familiales agricoles. Résultats et discussion. Les chefs d'exploitation, dont $90 \%$ sont des hommes, ont en moyenne 51 ans et un niveau de formation relativement bas. La diversité des espèces fruitières répertoriées varie suivant les sites. La com-

* Correspondance et tirés à part position spécifique du verger est aussi variable mais quatre espèces majeures (safoutier, oranger, manguier et avocatier) constituent $78 \%$ des plants recensés. Cette répartition corrobore les préférences exprimées par les producteurs pour ces espèces fruitières. Les jeunes arbres $(<10 \mathrm{ans})$, qui indiquent une dynamique de replantation, constituent $(15,21$ et 38$) \%$ des effectifs respectivement à Bokito, Foréké et Yaoundé. Toutefois d'importantes disparités intraspécifiques sont observées et discutées. En termes de contribution à la sécurité alimentaire du ménage, les arbres fruitiers, par rapport aux autres spéculations, occupent le $1^{\mathrm{er}}$, le $2^{\mathrm{e}}$ et le $4^{\mathrm{e}}$ rang à Bokito, Foréké et Yaoundé, respectivement. Les contraintes de production sont d'ordre parasitaire (maladies et ravageurs), agronomique (variétés, pratiques culturales, etc.) ou socioéconomique (intrants, foncier, etc.). Conclusion. Notre travail a permis d'obtenir d'importantes données sur les arbres fruitiers cultivés en zone humide du Cameroun. Les implications des principaux résultats sont discutées dans la perspective d'améliorer, en qualité, en quantité et dans la durée, ces productions.

Cameroun / arbre fruitier / enquête sur exploitations agricoles / zone périurbaine / facteur nuisible 


\section{Introduction}

Le développement des villes s'accompagne d'un accroissement de la population et pose en général des problèmes d'approvisionnement alimentaire. Cela conduit à s'interroger sur le devenir des systèmes de production agricole impliqués dans cet approvisionnement [1]. Les zones rurales où les terres sont à prédominance d'usage agricole sont des gros bassins de production. Mais les zones périurbaines de par leur proximité avec les marchés urbains constituent également d'importantes zones de production, en particulier pour les denrées périssables (fruits et légumes) qui sont généralement inadaptées aux transports lointains. Au Cameroun en particulier, la demande de fruits croît sans cesse dans les centres urbains [1].

Dans ce pays, les arbres fruitiers jouent un rôle important à plus d'un titre :

- comme source de revenus pour les ménages (figure 1) avec des productions diversifiées et étalées dans le temps (figure 2),

- comme apports nutritionnels de qualité [2] du fait notamment de la richesse de leurs productions en éléments minéraux, vitamines et fibres, qui s'accompagne d'une faible densité énergétique,

- comme éléments de restauration des équilibres écologiques après une déforestation et comme composante de diversification des productions (figures 3, 4),

- comme délimitation des propriétés foncières de par leur caractère pérenne,

\section{Figure 1.}

Fruits comme source de revenus pour le ménage (vente en bordure de route, zone humide du Cameroun).
- comme fonctions spécifiques: arbre d'ombrage ou à palabre,

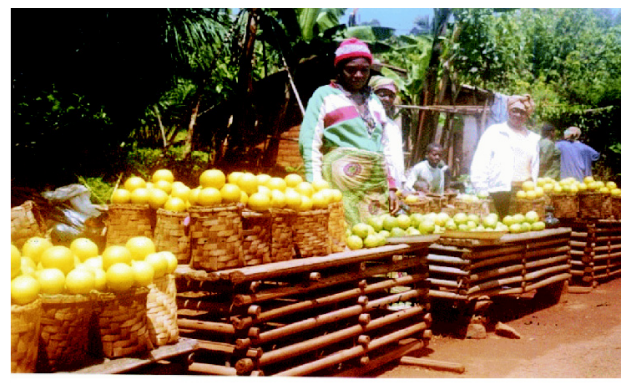

\section{Matériel et méthodes}

\subsection{Caractéristiques des sites choisis et champ couvert par l'enquête}

Pour notre étude sur l'état des productions fruitières en zone humide du Cameroun, trois contextes de production de fruits ont été retenus en tenant compte des conditions climatiques, de la proximité des marchés et des systèmes de culture : la zone périurbaine de Yaoundé, la zone de Foréké (Dschang périurbain) et la zone rurale de Bokito (figure 5). 


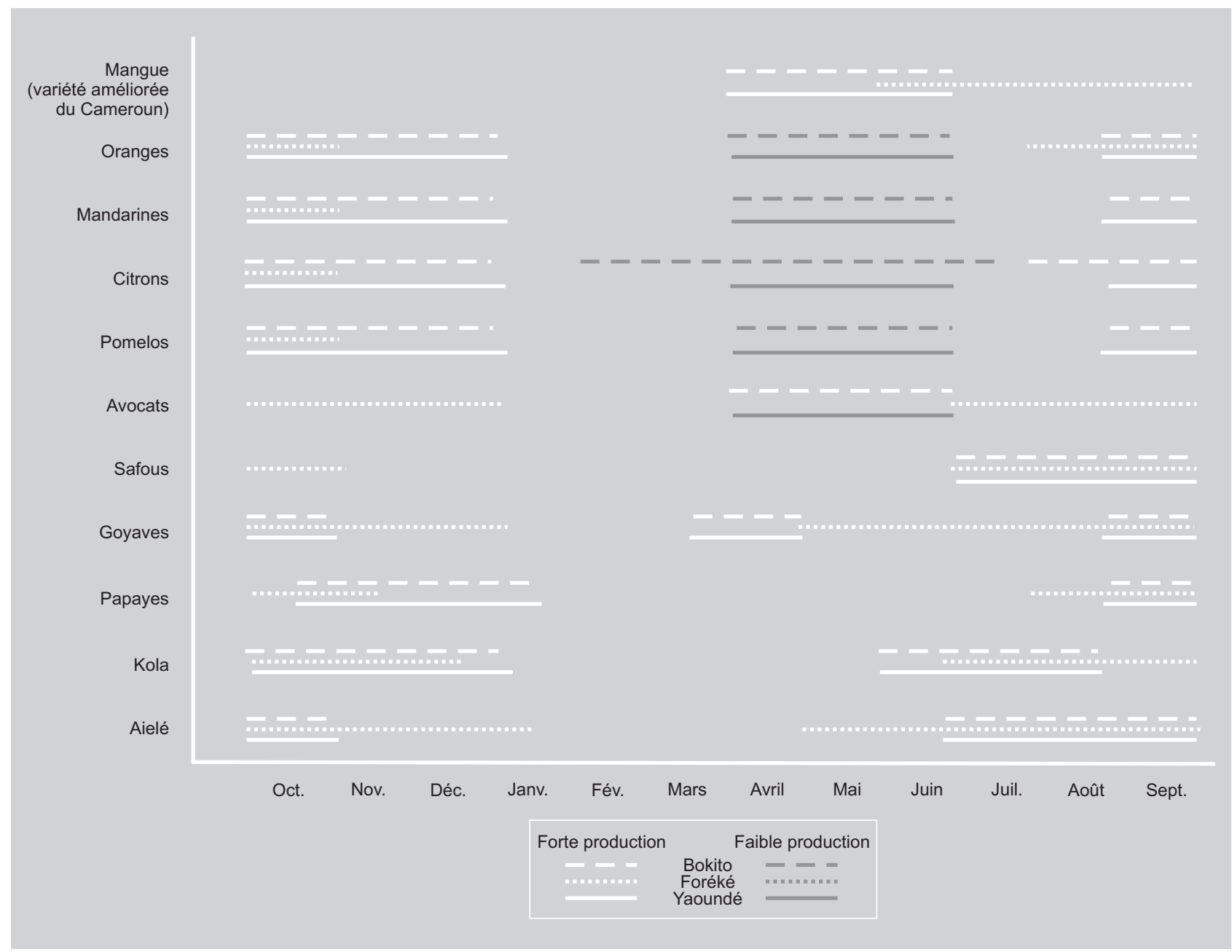

\subsubsection{Zone périurbaine de Yaoundé}

La zone périurbaine de Yaoundé est une zone forestière humide caractérisée par une pluviométrie moyenne annuelle variant de (1350 à 1700) mm et une altitude moyenne de $700 \mathrm{~m}$. La répartition bimodale de cette pluviométrie autorise deux cycles annuels de production pour plusieurs cultures, le premier s'étend de mars à juin et le second d'août à novembre. Dans cette région, la densité de population varie de (36 à 70) hab $\mathrm{km}^{-2}$ même s'il n'est pas rare de rencontrer des lieux où cette densité dépasse les $150 \mathrm{hab} \cdot \mathrm{km}^{-2}$ [7]. Les productions de fruits alimentent les marchés urbains de Yaoundé.

Les localités retenues pour notre étude (Nkolondom, Nkon Ndamba et Mvog Dzi- gui) ne sont éloignées que de (20 à 30) km de Yaoundé. À Nkolondom, la dominance est aux productions maraîchères avec le céleri comme spéculation majeure, mais les arbres fruitiers sont présents dans les exploitations familiales où ils se trouvent souvent en association avec les cultures vivrières ou les cacaoyers. Ces associations sont aussi fréquentes dans les autres localités étudiées (Nkon Ndamba et Mvog Dzigui). Le système de culture est plus ou moins intensif avec une pression foncière tirée par l'urbanisation.

\subsubsection{Zone rurale de Bokito}

La zone de Bokito est un important bassin de production de fruits situé en zone post forestière humide à pluviométrie bimodale. C'est une région de transition vers la savane.
Figure 2.

Périodes de production de quelques fruits exploités dans trois sites (Bokito, Foréké et Yaoundé), en zone humide du Cameroun. 
Figure 3.

Arbres fruitiers associés aux cultures vivrières dans une exploitation familiale agricole au Cameroun.

\section{Figure 4.}

Citronniers et safoutiers en association dans un verger familial à Bokito (zone humide du Cameroun).

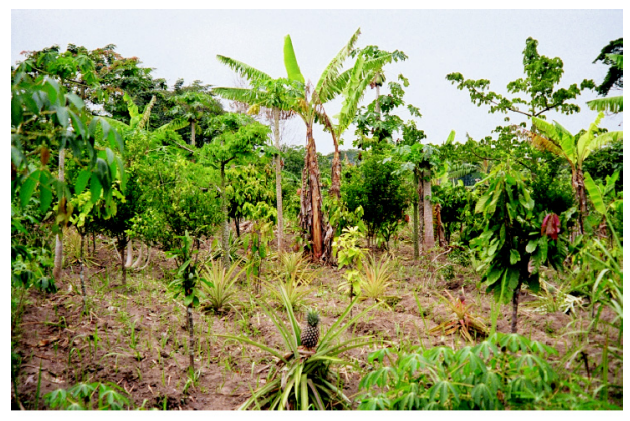

(> $200 \mathrm{hab} \cdot \mathrm{km}^{-2}$ ) [9]. C'est un important bassin de production de fruits et de cultures maraîchères qui alimente des marchés urbains plus ou moins éloignés : Dschang [(5 à 10) km], Bafoussam (80 km), Douala et Yaoundé $(>300 \mathrm{~km})$. Les localités retenues pour notre étude ont été : Banki, Litieu, Ntengué et Mbilé. Le système de culture y est très intensif avec une pression foncière tirée par la démographie et l'urbanisation.

\section{2. Échantillonnage}

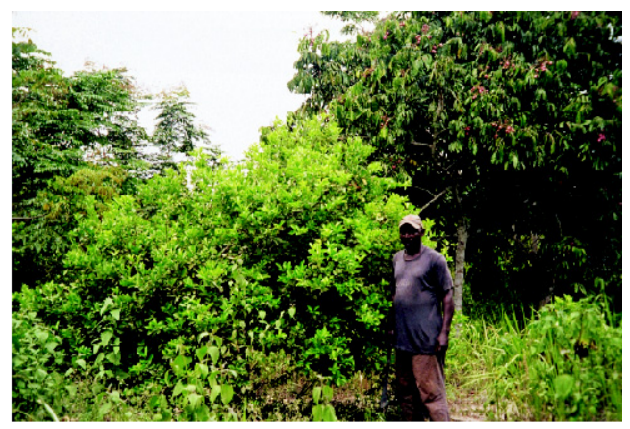

Dans l'ensemble, l'étude que nous avons menée a porté sur 193 familles axées sur des activités agricoles, dont 62 en zone périurbaine de Yaoundé, 51 dans la zone rurale de Bokito et 80 dans la zone périurbaine de Dschang, à Foréké. Les familles qui ont été interrogées dans chaque localité ont été choisies par tirage au sort à partir d'une liste de 30 à 40 exploitations agricoles qui pratiquent différentes activités ou spéculations. Les responsables de la localité [notables, chefs de village, responsable de groupe d'initiative commune (GIC)] ou organisation paysanne) et les agents de vulgarisation de zone (AVZ) ont été mis à contribution pour l'identification de ces exploitations agricoles. pour notre étude : Kedia, Begni et Bakoa. Les densités de population y sont plus faibles qu'en zone périurbaine de Yaoundé (29 hab $\mathrm{km}^{-2}$ ). Les marchés urbains les plus proches sont ceux de Bafia $(50 \mathrm{~km})$ et de Yaoundé $(170 \mathrm{~km})$. Le système de culture y est plus ou moins extensif. La pression foncière ici est tirée par les activités agricoles. L'association de plusieurs cultures sur une même parcelle constitue le système dominant. En effet, même s'il existe quelques parcelles en culture pure, les cacaoyères sont en général parsemées de bananiers, d'arbres fruitiers ou de palmiers à huile.

\subsubsection{Zone de Foréké (Dschang périurbain)}

La zone de Foréké est située sur les hauts plateaux. L'altitude varie de $700 \mathrm{~m}$ (Ntengué) à $1400 \mathrm{~m}$ (Lekwet Minmeto). La pluviométrie annuelle, qui peut varier de (1800 à 2000) $\mathrm{mm}$, a une répartition monomodale (climat à deux saisons). Cette région des hauts plateaux est très densément peuplée

\subsection{Visites de terrain et enquêtes}

Le questionnaire élaboré a été testé au préalable auprès de quelques exploitants pour aboutir, après révision, à la version définitive. Deux techniciens du programme "Fruits" de l'Institut de recherche agricole pour le développement (Irad, Cameroun) et deux ingénieurs agronomes diplômés de l'université de Dschang (Cameroun) ont mené les enquêtes. Après identification des exploitations à étudier, les rendez-vous ont été pris au fur et à mesure du déroulement des visites de terrain (deux à trois exploitations agricoles par jour).

Les questions relatives au profil du producteur ont été posées directement au chef d'exploitation ; celles relatives à la caractérisation des parcelles (état des arbres, présence des maladies et ravageurs, nombre de pieds par espèce, etc.) ont été directement renseignées sur le terrain par les agents 


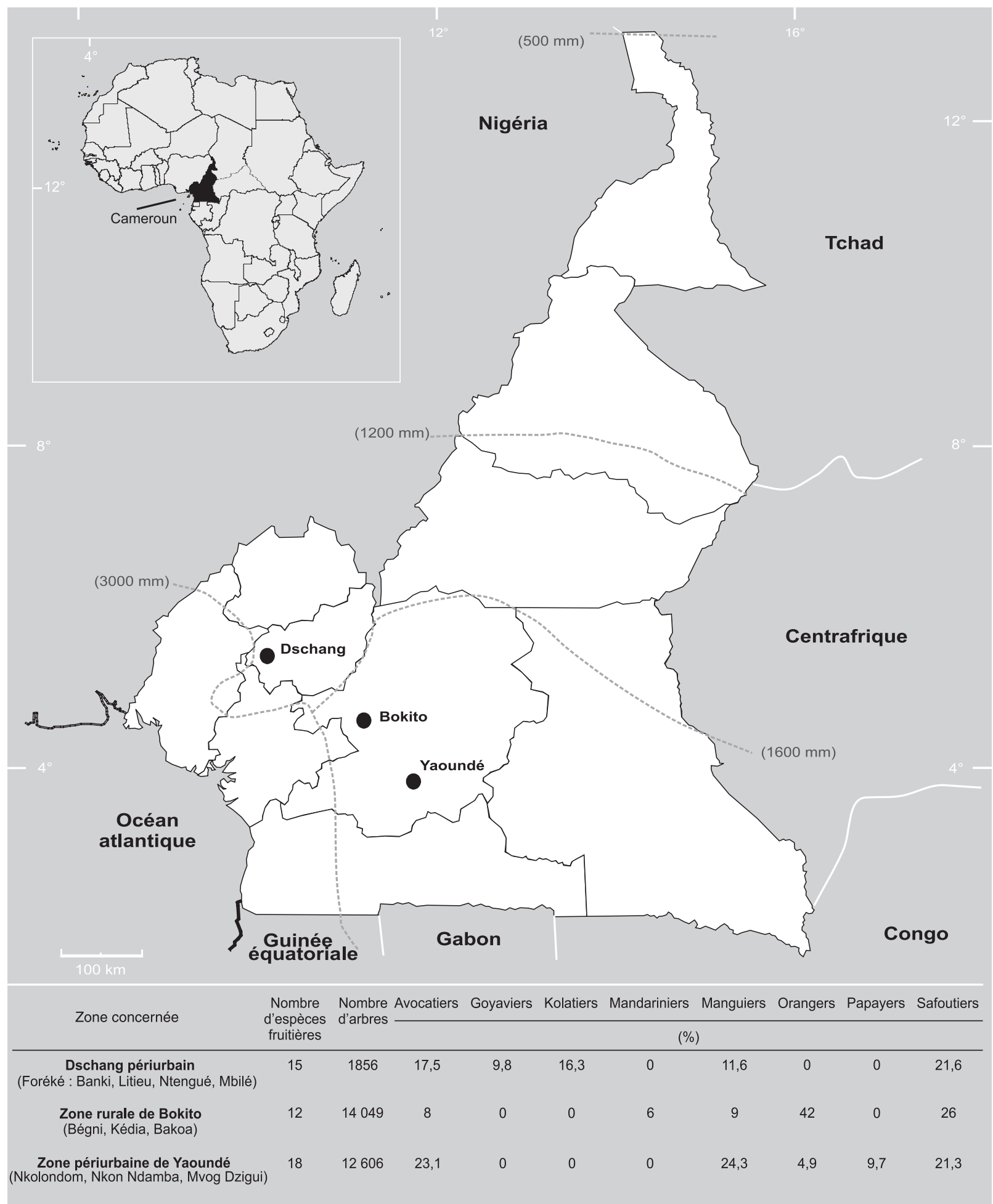

Figure 5.

Localisation des trois zones étudiées à l'occasion d'une enquête sur les cultures fruitières en zone humide du Cameroun et composition du verger fruitier. 
Tableau I.

Profil du chef d'exploitation familiale agricole parmi 193 familles d'exploitants agricoles interrogés à l'occasion d'une enquête sur les cultures fruitières en zone humide du Cameroun.

\begin{tabular}{|c|c|c|c|c|c|c|c|c|c|c|c|c|}
\hline \multirow[t]{2}{*}{ Site } & \multirow{2}{*}{$\begin{array}{l}\text { Nombre } \\
\text { de } \\
\text { ménages } \\
\text { étudiés }\end{array}$} & \multicolumn{2}{|c|}{$\begin{array}{l}\text { Sexe } \\
(\%)\end{array}$} & \multirow[t]{2}{*}{$\begin{array}{c}\text { Âge } \\
\text { (année) }\end{array}$} & \multicolumn{3}{|c|}{$\begin{array}{l}\text { Statut matrimonial } \\
\qquad(\%)\end{array}$} & \multicolumn{3}{|c|}{$\begin{array}{l}\text { Niveau de formation } \\
\qquad(\%)\end{array}$} & \multirow{2}{*}{$\begin{array}{c}\text { Nombre } \\
\text { moyen } \\
\text { d'enfants }\end{array}$} & \multirow{2}{*}{$\begin{array}{c}\text { Taux de } \\
\text { scolarisation } \\
(\%)\end{array}$} \\
\hline & & Homme & Femme & & $\begin{array}{l}\text { Célibataire } \\
\text { ou veuf }\end{array}$ & Monogame & Polygame & Aucune & Primaire & $\begin{array}{l}\text { Secondaire } \\
\text { et plus }\end{array}$ & & \\
\hline Bokito & 51 & 90,2 & 9,8 & 51,73 & 7,84 & 78,43 & 13,73 & 5,88 & 78,43 & 15,69 & 6,12 & 56,64 \\
\hline Foréké & 80 & 91,25 & 8,75 & 49,71 & 11,25 & 43,75 & 45 & 16,22 & 55,41 & 28,38 & 7,78 & 64,24 \\
\hline Yaoundé & 62 & 88,71 & 11,29 & 52,32 & 22,58 & 56,45 & 20,97 & 0 & 73,77 & 26,23 & 7,57 & 58,96 \\
\hline
\end{tabular}

enquêteurs en visitant les exploitations. Les données portant sur la contribution des productions fruitières au revenu et à l'alimentation du ménage, ainsi que l'évaluation du temps de travail et de la main-d'œuvre occasionnée par ces cultures, ont été collectées sous forme de notes ou scores correspondant au rang attribué par l'exploitant à la spéculation. Cette démarche a abouti à un classement des spéculations effectivement conduites dans l'exploitation familiale agricole à partir d'une échelle décroissante allant de la note 1 (production très importante) à la note 9 (production peu importante ou négligeable).

\subsection{Traitement des données et analyses statistiques}

Les fréquences relatives aux données qualitatives ont été calculées ainsi que les moyennes des variables continues. L'élaboration de tableaux de contingence a permis d'évaluer l'importance relative des productions fruitières par rapport aux autres spéculations et de déterminer les préférences des exploitants. Les neuf spéculations répertoriées ont conduit à définir neuf classes. Mais, en raison du nombre de réponses non exprimées dues au fait que chaque producteur n'a classé que les spéculations effectivement présentes dans son exploitation, certaines classes ont été regroupées. Finalement, trois classes ont donc été retenues : 1 , production très importante; 2 , production de moyenne importance ; 3 , production de faible importance.

Compte tenu de la nature catégorielle des facteurs étudiés (spéculations, espèces, etc.) et du caractère ordonné des rangs attribués, le modèle de régression des cotes proportionnelles [8], qui est une généralisation du modèle logistique aux données de rang, a été ajusté en utilisant la procédure CAtmod (Categorical Data Modeling) du logiciel SAS V.8. Dans notre analyse, les productions fruitières ont été considérées comme la spéculation de référence. Le rapport de cote $\left(\beta_{\mathrm{i}}\right)$ obtenu à partir du modèle représente la différence, à l'échelle logistique, entre la cote de la spéculation i et celle des productions fruitières :

$\beta_{\mathrm{i}}=\log \left[\mathrm{Ci} / \mathrm{C}_{\mathrm{O}}\right]$, où $\beta_{\mathrm{i}}$ est compris entre $-\infty$ et $+\infty ; C_{i}=P_{i} /\left(1-P_{i}\right)$ est la cote de la spéculation $i$ et $\mathrm{P}_{\mathrm{i}}$ est la probabilité pour que l'exploitant puisse ranger la spéculation $i$ dans la classe 3 (faible importance); $\mathrm{C}_{\mathrm{O}}$ est la cote de la spéculation de référence (production fruitière);

L'exponentiation de $\beta_{\mathrm{i}}$ exprime l'amplitude du rapport de cote et facilite l'interprétation des résuitats, en particulier, si $\exp \left(\beta_{\mathrm{i}}\right)>$ $\exp \left(\beta_{0}\right)$, la spéculation $i$ a plus de chance d'être classée moins importante que la production fruitière; si $\exp \left(\beta_{\mathrm{i}}\right)<\exp \left(\beta_{0}\right)$, la spéculation $i$ a peu de chance d'être classée moins importante que la production fruitière.

\section{Résultats et discussion}

\subsection{Profil du producteur}

L'analyse des résultats permettant de déterminer le profil du chef d'exploitation agricole (tableau I) montre que ceux qui ont été 
interrogés sont en grande majorité des hommes (moins de $10 \%$ de femmes). Par ailleurs, le régime polygamique est prédominant chez les exploitants de Foréké ( $45 \%$ ). Il est connu, en effet, que la polygamie constitue en général une tradition forte chez les Bamilékés de l'ouest du Cameroun [9]. En revanche, les célibataires sont relativement nombreux parmi les exploitants de la zone périurbaine de Yaoundé $(22,6 \%)$. Cela pourrait en partie s'expliquer par la prédominance du maraîchage dans cette zone, activité assez récente, exigeante en main-d'œuvre, qui serait plus facilement adopté par les jeunes que par les vieux [7]. Enfin, plus de $75 \%$ des chefs d'exploitation enquêtés ont au plus le niveau primaire et $24 \%$ le niveau secondaire. Ce niveau de formation relativement bas suggère que, pour la transmission des connaissances techniques, il faudra de préférence adopter une démarche participative avec des essais comparatifs en milieu paysan.

\subsection{Diversité des espèces fruitières, composition du verger et âge des plants}

Au total 19 espèces fruitières ont été répertoriées dans les trois zones étudiées et 28511 arbres ont été recensés (tableau II).

L'analyse de la composition spécifique du verger montre que, en zone périurbaine de Yaoundé, les espèces dominantes sont, par ordre décroissant, le manguier, l'avocatier, le safoutier, le papayer et les agrumes (tableau II). La plus grande diversité (18 espèces sur les 19 répertoriées) y est aussi observée. Cela pourrait en partie s'expliquer par la proximité de la ville (populations cosmopolites, demande forte et diversifiée, etc.). Dans la zone de Foréké (Dschang périurbain), 15 espèces fruitières sur les 19 ont été identifiées, alors que, dans la zone rurale de Bokito, il n'a été possible de répertorier que 12 espèces.

Tandis qu'à Foréké les cinq espèces dominantes sont le safoutier, l'avocatier, le kolatier, le manguier et le goyavier, à Bokito, l'essentiel du verger est constitué d'orangers, de safoutiers, de manguiers, d'avocatiers et de mandariniers. Nous avons pu noter par ailleurs que c'est en zones périurbaines qu'ont été trouvées quelques espèces récemment introduites par l'Institut de recherche agricole pour le développement (cerisier de Cayenne, cour de bœuf, jacquier, etc.). Mais les espèces très faiblement représentées (moins de 10 pieds au total) n'ont pas été mentionnées dans le tableau III

Les proportions par tranche d'âge rendant compte de l'âge des plants constituent des indices intéressants de caractérisation. Une forte proportion de jeunes arbres ( $<10$ ans) dénoterait, par exemple, une dynamique de replantation ou de repeuplement (population subspontanée) qui serait un indicateur de la durabilité du système. Cette tranche de jeunes arbres est représentée en moyenne par $(15,5,21,3$ et 38,6)\% des populations d'arbres fruitiers à Bokito, Foréké et Yaoundé, respectivement. Des disparités importantes existent cependant entre espèces. Par exemple, à Bokito, le pourcentage de jeunes arbres varie de 3,4 (pomme Cythère) à 50,1 (citronnier). Par ailleurs, l'oranger qui constitue l'espèce dominante dans cette zone n'a que $12 \%$ de plants de moins de 10 ans. Il nous est apparu particulièrement intéressant de savoir ce qui pouvait expliquer l'importante replantation de citronniers constatée. En interrogeant les producteurs concernés (16 personnes), deux raisons principales ont été avancées :

- D'une part, le citron, en fait le petit citron qui est la lime mexicaine, est très demandé sur le marché de Yaoundé où le filet de $50 \mathrm{~kg}$ peut être vendu jusqu'à 25000 FCFA, à comparer aux (10 000 à 12 000) FCFA obtenus par la vente des oranges. Les producteurs indiquent que plusieurs revendeuses viennent de Yaoundé acheter sur place ces citrons.

- D'autre part, le citron produit abondamment et de façon étalée, contrairement aux autres agrumes. Deux pics de production existent dans la zone (juin-juillet et octobre-novembre), mais les citronniers ont presque en permanence des fleurs et des fruits. Ils procurent donc constamment des revenus aux producteurs qui signalent en outre que la production d'octobre à novembre coïncide avec une très forte demande de 


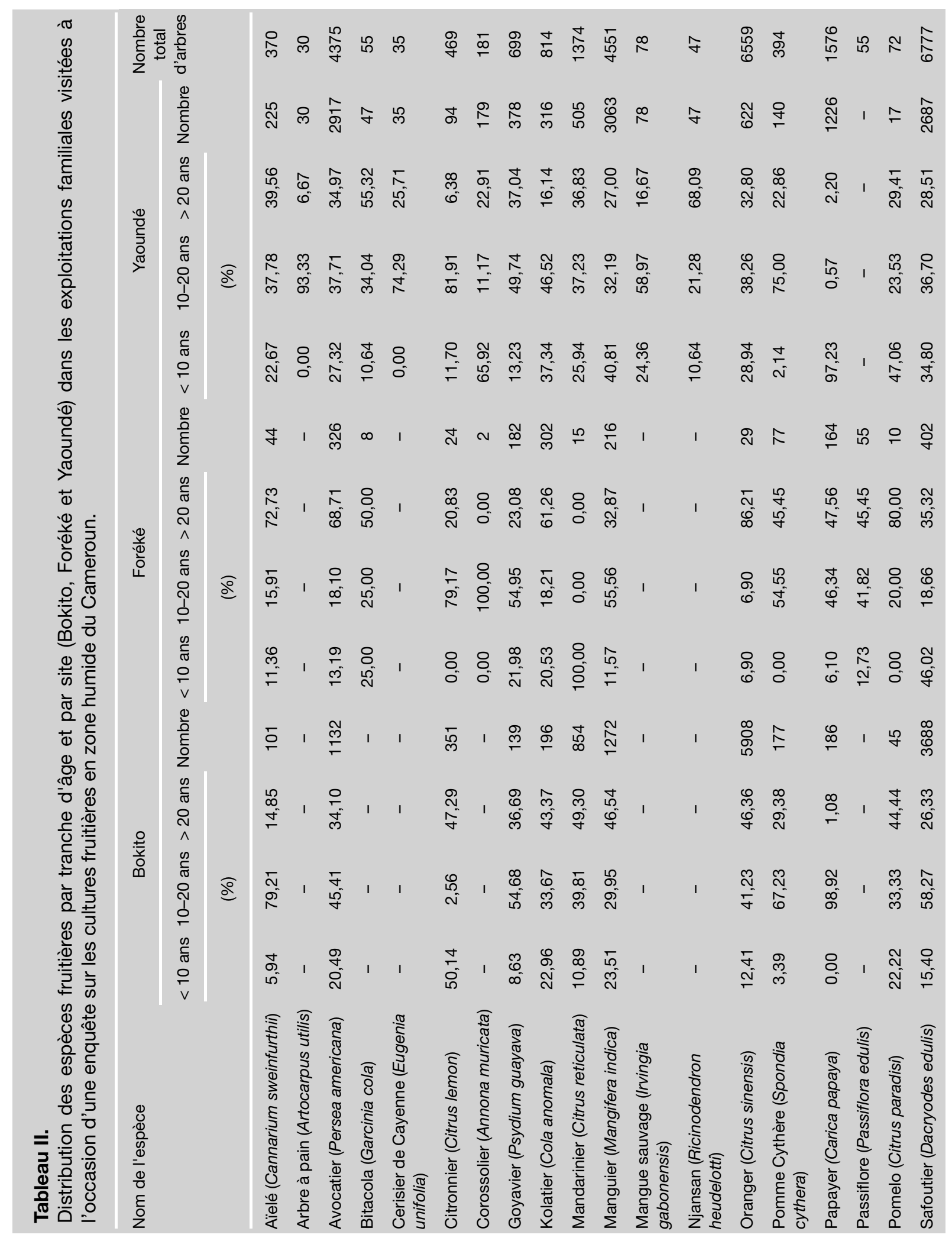

380 Fruits, vol. 61 (6) 
Tableau III.

Contribution des arbres fruitiers au revenu du ménage pour 193 familles d'exploitants agricoles interrogés à l'occasion d'une enquête sur les cultures fruitières dans trois sites de la zone humide du Cameroun. Les fréquences des réponses (\%) sont exprimées en fonction des classes.

\begin{tabular}{|c|c|c|c|c|c|c|c|c|c|c|c|c|c|c|c|}
\hline \multirow[t]{3}{*}{ Spéculation } & \multicolumn{5}{|c|}{ Bokito } & \multicolumn{5}{|c|}{ Foréké } & \multicolumn{5}{|c|}{ Yaoundé } \\
\hline & \multicolumn{3}{|c|}{$\begin{array}{l}\text { Fréquence } \\
\text { des réponses }\end{array}$} & \multirow[t]{2}{*}{$\operatorname{Exp}(\beta)$} & \multirow[t]{2}{*}{ Rang } & \multicolumn{3}{|c|}{$\begin{array}{l}\text { Fréquence } \\
\text { des réponses }\end{array}$} & \multirow[t]{2}{*}{$\operatorname{Exp}(\beta)$} & \multirow[t]{2}{*}{ Rang } & \multicolumn{3}{|c|}{ Fréquence des réponses } & \multirow[t]{2}{*}{$\operatorname{Exp}(\beta)$} & \multirow[t]{2}{*}{ Rang } \\
\hline & 1 & 2 & 3 & & & 1 & 2 & 3 & & & 1 & 2 & 3 & & \\
\hline Apiculture & - & - & - & - & - & 3 & 3 & 6 & 1,39 & 7 & 5 & 4 & 3 & 1,43 & 5 \\
\hline Cacaoyer & 45 & 5 & 5 & 0,63 & 1 & 27 & 5 & 5 & 0,60 & 2 & 8 & 19 & 7 & 0,74 & 3 \\
\hline Caféier & - & - & - & - & - & 32 & 5 & 5 & 0,57 & 1 & - & - & - & - & - \\
\hline Élevage & 5 & 7 & 6 & 1,38 & 5 & 7 & 15 & 11 & 1,23 & 6 & 5 & 7 & 10 & 1,47 & 6 \\
\hline Maraîchage & - & - & - & - & - & 13 & 5 & 5 & 0,77 & 4 & 16 & 5 & 5 & 0,72 & 2 \\
\hline Palmier & 5 & 26 & 5 & 1,30 & 4 & 5 & 8 & 16 & 1,59 & 8 & 5 & 16 & 17 & 1,49 & 7 \\
\hline Sylviculture & - & - & - & - & - & 5 & 6 & 25 & 1,89 & 9 & - & - & - & - & - \\
\hline Vivriers & 13 & 29 & 6 & 1,13 & 3 & 60 & 38 & 6 & 0,65 & 3 & 61 & 16 & 5 & 0,65 & 1 \\
\hline Arbre fruitier & 33 & 17 & 5 & 0,78 & 2 & 11 & 47 & 15 & 1,15 & 5 & 30 & 42 & 10 & 0,92 & 4 \\
\hline
\end{tabular}

citrons sur le marché de Yaoundé. Seuls deux producteurs sur les seize concernés par l'exploitation de citronniers ont évoqué la moindre sensibilité du citron vis-à-vis des maladies par rapport aux orangers et aux autres agrumes moins sujets à de nouvelles plantations. Il convient de signaler que les citronniers sont bien connus pour leur tolérance à la cercosporiose, maladie particulièrement grave sur les agrumes en zone humide [10-12]. À noter que le citron entre dans la composition de plusieurs recettes de cuisine ou de la pharmacopée traditionnelle.

À Foréké, plus de $46 \%$ des safoutiers ont moins de 10 ans, ce qui peut traduire un intérêt particulier des exploitants pour cette espèce très demandée pour une autoconsommation ou sur les marchés nationaux et régionaux. Dans cette même région, environ $69 \%$ d'avocatiers, $61 \%$ de kolatiers, $86 \%$ d'orangers et $73 \%$ d'aïelés de plus de 20 ans ont été décomptés. En-dehors des safoutiers, les replantations ou repeuplements importants concernent surtout le goyavier et le kolatier dans la mesure où les autres espèces [bitacola (Garcinia cola), mandariniers] représentent en valeur absolue des quantités assez faibles. En revanche, dans la zone périurbaine de Yaoundé, près de $66 \%$ des corossoliers ont moins de 10 ans, ce qui témoigne d'une dynamique de replantation de cette espèce. Les papayers se retrouvent globalement et de par leur cycle normal de culture dans cette tranche d'âge.

\subsection{L'arboriculture fruitière par rapport aux autres spéculations}

L'analyse des données portant sur l'étude de la contribution des arbres fruitiers au revenu des ménages révèle que ceux-ci $[\exp (\beta)=$ 0,78 ] occupent la seconde position après le cacaoyer $[\exp (\beta)=0,63]$ à Bokito, alors que, à Foréké, ils occupent le cinquième rang derrière le caféier, le cacaoyer, les cultures vivrières et le maraîchage (tableau III). La même tendance a été observée à Yaoundé, à cela près que, dans cette zone, les cultures vivrières $[\exp (\beta)=0,65]$ rapportent le plus de revenu au ménage, devant le maraîchage $[\exp (\beta)=0,72]$, le cacaoyer $[\exp (\beta)=0,74]$ et enfin les productions fruitières $[\exp (\beta)=$ $0,92]$. Les fruitiers se classent donc parmi les cinq spéculations les plus génératrices de revenus quel que soit le site considéré. 
Tableau IV.

Contribution des arbres fruitiers à l'alimentation de la famille pour 193 familles d'exploitants agricoles interrogés à l'occasion d'une enquête sur les cultures fruitières dans trois sites de la zone humide du Cameroun. Les fréquences des réponses (\%) sont exprimées en fonction des classes.

\begin{tabular}{|c|c|c|c|c|c|c|c|c|c|c|c|c|c|c|c|}
\hline \multirow[t]{3}{*}{ Spéculation } & \multicolumn{5}{|c|}{ Bokito } & \multicolumn{5}{|c|}{ Foréké } & \multicolumn{5}{|c|}{ Yaoundé } \\
\hline & \multicolumn{3}{|c|}{$\begin{array}{l}\text { Fréquence des } \\
\text { réponses }\end{array}$} & \multirow[t]{2}{*}{$\operatorname{Exp}(\beta)$} & \multirow[t]{2}{*}{ Rang } & \multicolumn{3}{|c|}{$\begin{array}{l}\text { Fréquence des } \\
\text { réponses }\end{array}$} & \multirow[t]{2}{*}{$\operatorname{Exp}(\beta)$} & \multirow[t]{2}{*}{ Rang } & \multicolumn{3}{|c|}{$\begin{array}{l}\text { Fréquence des } \\
\text { réponses }\end{array}$} & \multirow[t]{2}{*}{$\operatorname{Exp}(\beta)$} & \multirow[t]{2}{*}{ Rang } \\
\hline & 1 & 2 & 3 & & & 1 & 2 & 3 & & & 1 & 2 & 3 & & \\
\hline Apiculture & - & - & - & - & - & 2 & 3 & 6 & 1,42 & 7 & 2 & 7 & 7 & 1,57 & 6 \\
\hline Cacaoyer & 10 & 5 & 5 & 1,08 & 4 & 0 & 16 & 11 & 1,48 & 8 & 26 & 18 & 5 & 0,75 & 3 \\
\hline Caféier & - & - & - & - & - & 0 & 2 & 18 & 2,42 & 9 & - & - & - & - & - \\
\hline Élevage & 5 & 8 & 5 & 1,38 & 5 & 2 & 23 & 9 & 1,21 & 6 & 5 & 13 & 7 & 1,25 & 5 \\
\hline Maraîchage & - & - & - & - & - & 14 & 9 & 3 & 0,65 & 3 & 27 & 4 & 5 & 0,62 & 2 \\
\hline Palmier & 35 & 13 & 5 & 0,79 & 3 & 11 & 22 & 5 & 0,84 & 4 & 5 & 16 & 20 & 1,66 & 6 \\
\hline Sylviculture & - & - & - & - & - & 12 & 17 & 12 & 0,99 & 5 & - & - & - & - & - \\
\hline Vivriers & 41 & 5 & 6 & 0,71 & 2 & 78 & 23 & 7 & 0,51 & 1 & 50 & 10 & 7 & 0,61 & 1 \\
\hline Arbre fruitier & 14 & 38 & 6 & 0,23 & 1 & 47 & 31 & 5 & 0,59 & 2 & 12 & 48 & 8 & 1,08 & 4 \\
\hline
\end{tabular}

Les cultures fruitières sont prédominantes pour l'apport à l'alimentation des ménages (tableau IV) à Bokito $[\exp (\beta)=0,23]$, où ces productions devancent celles des cultures vivrières $[\exp (\beta)=0,71]$. Mais il convient de noter qu'il s'agit en réalité d'une contribution indirecte à l'alimentation des ménages car, d'après les personnes interrogées, le produit de la vente des fruits permet d'acheter d'autres denrées alimentaires (riz, poissons, viandes, condiments, etc.). La bonne position des cultures fruitières ne reflète donc pas une consommation directe de fruits qui viendrait supplanter celle de tout autre aliment. Pour les sites de Foréké et de Yaoundé, où ce sont les cultures vivrières qui contribuent le plus à l'alimentation des ménages, les productions fruitières occupent respectivement la seconde $[\exp (\beta)=$ $0,59]$ et la quatrième place $[\exp (\beta)=1,08]$ ).

Les données permettant d'évaluer les besoins en main-d'œuvre requis par les principales spéculations des exploitants agricoles enquêtés révèlent que, de toutes les activités agropastorales menées à Bokito et à Foréké, ce sont les cultures fruitières qui arrivent en dernière position avec des amplitudes de rapport de cote $\exp (\beta)=$ 2,13 et de $\exp (\beta)=1,48$, respectivement (tableau V). Par conséquent, l'arboriculture fruitière serait l'activité la moins exigeante en main-d'œuvre sur ces deux sites. En revanche, dans la zone périurbaine de Yaoundé, ces productions occupent une position intermédiaire entre les activités très exigeantes en main-d'œuvre (cultures vivrières, marâichage et cacaoculture) et celles qui le sont beaucoup moins (apiculture, élevage et palmier à huile traditionnel).

Il apparaît donc que, dans les zones de Bokito et de Foréké, l'arboriculture fruitière, bien que contribuant fortement à l'alimentation et au revenu des ménages, est relativement peu exigeante en main d'œuvre. Comment expliquer cette situation apparemment paradoxale? En fait, les cultures fruitières étant, dans ces systèmes de production, souvent associées aux cacaoyers, aux caféiers ou aux cultures vivrières ne bénéficient que de manière indirecte des soins apportés à ces cultures dominantes. Ainsi, le producteur qui défriche ou traite sa cacaoyère contre les maladies et ravageurs apporte les mêmes soins aux arbres fruitiers 
Tableau V.

Exigence des arbres fruitiers en main-d'œuvre pour 193 familles d'exploitants agricoles interrogés à l'occasion d'une enquête sur les cultures fruitières dans trois sites de la zone humide du Cameroun. Les fréquences des réponses (\%) sont exprimées en fonction des classes.

\begin{tabular}{|c|c|c|c|c|c|c|c|c|c|c|c|c|c|c|c|}
\hline \multirow[t]{3}{*}{ Spéculation } & \multicolumn{5}{|c|}{ Bokito } & \multicolumn{5}{|c|}{ Foréké } & \multicolumn{5}{|c|}{ Yaoundé } \\
\hline & \multicolumn{3}{|c|}{$\begin{array}{l}\text { Fréquence des } \\
\text { réponses }\end{array}$} & \multirow[t]{2}{*}{$\operatorname{Exp}(\beta)$} & \multirow[t]{2}{*}{ Rang } & \multicolumn{3}{|c|}{$\begin{array}{l}\text { Fréquence des } \\
\text { réponses }\end{array}$} & \multirow[t]{2}{*}{$\operatorname{Exp}(\beta)$} & \multirow[t]{2}{*}{ Rang } & \multicolumn{3}{|c|}{$\begin{array}{l}\text { Fréquence des } \\
\text { réponses }\end{array}$} & \multirow[t]{2}{*}{$\operatorname{Exp}(\beta)$} & \multirow[t]{2}{*}{ Rans } \\
\hline & 1 & 2 & 3 & & & 1 & 2 & 3 & & & 1 & 2 & 3 & & \\
\hline Apiculture & - & - & - & - & - & 3 & 5 & 5 & 1,25 & 5 & 2 & 2 & 5 & 1,53 & 5 \\
\hline Cacaoyer & 50 & 7 & 5 & 0,50 & 1 & 21 & 7 & 5 & 0,66 & 3 & 20 & 23 & 5 & 0,80 & 3 \\
\hline Caféier & - & - & - & - & - & 61 & 12 & 5 & 0,52 & 1 & - & - & - & - & - \\
\hline Élevage & 2 & 5 & 13 & 1,81 & 4 & 2 & 15 & 10 & 1,44 & 7 & 3 & 10 & 11 & 1,53 & 5 \\
\hline Maraîchage & - & - & - & - & - & 18 & 11 & 8 & 0,82 & 4 & 30 & 9 & 5 & 0,62 & 2 \\
\hline Palmier & 5 & 45 & 1 & 0,96 & 3 & 5 & 7 & 16 & 1,59 & 8 & 3 & 19 & 16 & 1,54 & 6 \\
\hline Sylviculture & - & - & - & - & - & 4 & 24 & 12 & 1,31 & 6 & - & - & - & - & - \\
\hline Vivriers & 39 & 7 & 5 & 0,54 & 2 & 37 & 19 & 5 & 0,63 & 2 & 52 & 9 & 5 & 0,54 & 1 \\
\hline Arbre fruitier & 0 & 2 & 5 & 2,13 & 5 & 5 & 32 & 25 & 1,48 & 9 & 15 & 44 & 11 & 1,04 & 4 \\
\hline
\end{tabular}

associés, mais, lors du questionnaire réalisé lors de notre étude, ces opérations n'ont pas été mentionnées comme attribuées en particulier aux arbres fruitiers. Par ailleurs, les exploitants pour qui les arbres fruitiers servent en premier lieu à la délimitation de la propriété foncière n'apportent logiquement pas beaucoup de soins à ces arbres lorsqu'ils sont bien développés. Le même raisonnement peut être tenu lorsqu'il s'agit d'arbres spontanés.

\subsection{Place des arbres fruitiers dans les systèmes de culture et contraintes de production}

\subsubsection{Les arbres fruitiers dans les systèmes de culture}

Les arbres fruitiers ont été trouvés dans les parcelles en association avec les cultures vivrières, avec les cacaoyers ou les caféiers (arbres d'ombrage), ou avec les palmiers à huile. Mais ils ont aussi été observés autour des cases, dans les jachères ou dans les haies vives pour la délimitation des propriétés foncières. Leur présence dans les jachères résulterait de leur association à des cultures vivrières antérieures ou encore d'un développement spontané.

\subsubsection{Contraintes des productions fruitières}

Une analyse des divers facteurs pouvant affecter la production des arbres fruitiers révèle que les problèmes parasitaires constituent les contraintes majeures de production pour la quasi-totalité des espèces fruitières. Les données présentées dans ce contexte pour la zone périurbaine de Yaoundé (tableau $V I$ ) sont représentatives également des principaux freins au développement des cultures fruitières dans les deux autres zones étudiées lors de nos enquêtes.

Les chutes de fruits et de fleurs relevées chez presque toutes les espèces peuvent en partie être imputables aux attaques parasitaires. Les carences minérales concernent surtout un manque de bore chez les papayers et le problème se manifeste par des déformations des fruits.

Notons qu'une des contraintes récurrentes, mais non agronomique, est liée à la commercialisation de ces produits périssables [13] bien que ce problème ne soit pas 
Tableau VI.

Principales contraintes aux productions fruitières en zone périurbaine de Yaoundé d'après 193 familles d'exploitants agricoles interrogés à l'occasion d'une enquête sur les cultures fruitières en zone humide du Cameroun.

\begin{tabular}{|c|c|c|c|c|c|c|}
\hline \multirow[t]{2}{*}{$\begin{array}{l}\text { Arbre fruitier } \\
\text { concerné }\end{array}$} & $\begin{array}{l}\text { Absence de } \\
\text { floraison }\end{array}$ & $\begin{array}{c}\text { Chute de fleurs ou } \\
\text { de fruits }\end{array}$ & $\begin{array}{l}\text { Maladies et } \\
\text { ravageurs }\end{array}$ & Carences minérales & Autres & Faible production \\
\hline & \multicolumn{6}{|c|}{$(\%)$} \\
\hline Avocatier & - & 1,5 & 97,1 & - & 1,4 & - \\
\hline Citronnier & - & 14,3 & 85,7 & - & - & - \\
\hline Kolatier & 3,1 & 3,1 & 81,3 & 6,3 & - & 6,3 \\
\hline Goyavier & - & 1,1 & 93,7 & 2,1 & 1,1 & 2,1 \\
\hline Mandarinier & - & 5 & 95 & - & . & - \\
\hline Manguier & - & 20,3 & 76,6 & - & 0,8 & 2,3 \\
\hline Oranger & - & 2,9 & 97,1 & - & - & - \\
\hline Papayer & - & 4,1 & 26,5 & 67,3 & - & 2 \\
\hline Pomelo & - & - & 100 & - & - & - \\
\hline Pomme Cythère & 5,9 & 5,9 & 76,5 & 11,8 & - & - \\
\hline Safoutier & 3,9 & 29,1 & 64,1 & - & - & 2,9 \\
\hline
\end{tabular}

très souligné en zone périurbaine de Yaoundé de par l'accès facile des productions fruitières aux marchés urbains où les fruits sont très demandés (moins de $20 \mathrm{~km}$ et route bitumée pour Nkolondom et Nkon Ndamba).

Le problème de la qualité du matériel végétal, bien que crucial, semble beaucoup moins perçu par les producteurs. Il transparaît cependant de façon indirecte lorsque certains exploitants interrogés évoquent la mauvaise qualité des fruits (acidité, faible calibre, etc.), le temps très long entre la plantation des arbres et leur première production ou encore la pénibilité de la récolte sur des arbres très hauts. Le fait que la majorité des arbres fruitiers soient des plants de semis (sans multiplication végétative, sans amélioration génétique conventionnelle) peut être cause d'une faible performance du verger (productivité, qualité des fruits et surtout difficulté à récolter ou à traiter lorsque la hauteur des frondaisons est élevée). Par ailleurs, l'engouement affiché par certains producteurs de la zone humide à marcotter, par exemple le safoutier, dès lors qu'ils ont perçu les avantages liés à cette technique est assez révélateur du problème de la qualité du matériel végétal.
L'application sans discernement, aux arbres fruitiers associés à des cultures de rente (café, cacao), des traitements pesticides destinés à ces cultures de rentes est également problématique car les traitements peuvent en effet se révéler totalement inappropriés aux problèmes sanitaires des cultures fruitières. Ainsi, les fongicides couramment appliqués contre la pourriture brune du cacaoyer n'ont aucune efficacité vis-à-vis de la cercosporiose des agrumes. Enfin, les dosages des pesticides signalés par les producteurs révèlent une non maîtrise, par ces exploitants, des techniques de traitements phytosanitaires ; de nombreux effets négatifs peuvent en découler (pollution de l'environnement, résidus toxiques dans les récoltes, etc.).

\subsubsection{Rôles des fruitiers et utilisation des récoltes}

Les résultats de notre étude sur la culture des espèces fruitières dans les exploitations familiales agricoles en zone humide du Cameroun permettent de constater que " produire pour la consommation et pour la commercialisation " est un rôle reconnu à ces spéculations par la totalité des exploitants enquêtés. Le rôle des arbres fruitiers 
pour délimiter les propriétés foncières ou comme élément fournissant de l'ombrage a aussi été noté par de nombreux exploitants. Quelques producteurs reconnaissent que la transformation des fruits peut apporter une plus-value même s'ils disent ne pas en faire eux-mêmes. Par ailleurs, d'après les personnes interrogées, de nombreux arbres fruitiers sont réputés pour avoir des vertus médicinales. Ainsi en est-il pour la zone périurbaine de Yaoundé du manguier (61,8 \% des exploitants enquêtés), du safoutier $(41,8 \%)$, du goyavier $(30,9 \%)$, du papayer (23,6\%), de l'avocatier (21,8\%), du citronnier et de l'oranger (16,3\%), du kolatier $(14,5 \%)$, du bitacola $(12,7 \%)$, du njansan $(7,2 \%)$ et de la pomme Cythère $(5,4 \%)$. Les lieux de vente de ces fruits sont assez divers : les marchés locaux, le bord des routes et les marchés urbains ou régionaux. Peu d'exploitants valorisent les fruits dépréciés inaptes à la vente ou à la consommation par leur utilisation dans l'alimentation des animaux (27\% par exemple en zone périurbaine de Yaoundé). Une telle forme de valorisation pourrait pourtant permettre d'exploiter les écarts de tri ou les résidus comme cela est le cas au Brésil où il serait possible de substituer $100 \%$ du maïs inclus dans la ration animale par de la pulpe d'orange [14, 15].

\section{Conclusion}

L'enquête réalisée sur les cultures fruitières dans les exploitations familiales agricoles en zone humide du Cameroun a permis d'obtenir un certain nombre d'informations aptes à caractériser le profil du producteur, les activités pratiquées dans l'exploitation familiale agricole, la diversité des espèces fruitières, leur importance relative, les contraintes de leur production et la destination des récoltes.

Les arbres fruitiers présents dans les zones étudiées sont en majorité des plants spontanés (100\% pour le Njansan ou Ricinodendron beudelotii, $48 \%$ pour le manguier en zone périurbaine de Yaoundé) ou des plants de semis issus de sélection locale ; moins de $1 \%$ d'entre eux sont issus de variétés améliorées conventionnelles. Cette faible présence de plants greffés, mar- cottés ou sélectionnés dénote un problème de diffusion ou d'adoption des résultats de la recherche agricole. Les avocatiers, les manguiers, les safoutiers, les agrumes et les papayers sont les espèces les plus représentées. Toutefois, la répartition globale des arbres en tranches d'âge, telle que nous l'avons faite, masque des disparités importantes parmi les espèces. Pour certaines d'entre elles, des fortes proportions de jeunes arbres ( $<10$ ans) ont été observées (cas du citronnier à Bokito ou du safoutier à Foréké) ; cela suggérerait une dynamique de replantation ou de repeuplement qui serait un indicateur de durabilité de l'arboriculture fruitière. Dans une perspective de développement des productions fruitières, une telle dynamique ne peut efficacement être accompagnée que si les raisons profondes de ces replantations sont connues. À Bokito par exemple, la replantation de citronniers s'est révélée être surtout stimulée par une forte demande de citrons sur le marché urbain de Yaoundé. L'accompagnement de cette dynamique pourrait consister en des appuis au plan agrotechnique (matériel végétal, techniques culturales, gestion des maladies et ravageurs, etc.) mais aussi au plan socioéconomique (organisation locale, stratégies de financement et de commercialisation, etc.)

Pour les espèces présentant de fortes proportions de vieux plants ( $>20$ ans) qui feraient l'objet de perspective du développement, il faudrait envisager la régénération des arbres ; en effet, ce type de matériel végétal essentiellement issu de semis pose parfois des problèmes de productivité, de sensibilité aux maladies, de qualité des fruits, de longueur du cycle, de technique de récolte ou de traitement du fait de la hauteur des arbres. Des techniques de greffage sur repousses peuvent permettre une reconversion variétale lors de la régénération. Le marcottage du safoutier qui est une technique en cours de vulgarisation est un exemple d'accompagnement que peut apporter la recherche agricole.

Les résultats de notre étude constituent une base de réflexion sur les actions à entreprendre pour améliorer et maintenir une production de fruits de qualité dans la zone humide du Cameroun prospectée. 
Bien que pour certaines contraintes au développement de ces cultures il soit nécessaire de réaliser un diagnostic plus ciblé, l'utilisation d'un matériel végétal performant, la maitrise des techniques de lutte contre les bioagresseurs des arbres fruitiers, la valorisation des produits après récolte (commercialisation, transformation) sont autant d'actions qui pourraient être menées. Ces actions contribueraient à améliorer durablement en qualité et en quantité la production fruitière dans la région considérée tout en assurant leur innocuité pour les consommateurs (sûreté alimentaire). Il conviendra par ailleurs d'aborder de façon plus détaillée, lors d'études ultérieures, la connaissance des pratiques agricoles paysannes et de leur impact sur la production. La compréhension de la stratégie des producteurs dans l'exploitation fruitière serait aussi un élément important à prendre en compte.

\section{Remerciements}

Ce travail a été réalisé avec l'appui financier du "Pôle de compétence en partenariat" (PCP Grand Sud Cameroun). Nous remercions Joseph Marie Nouga, Jean-Dieudonné Eyenga, Jacques Daniel Nguetsop, Honoré Mbah et Léonard Enama Ngah pour leur collaboration.

\section{Références}

[1] Temple L., Quantification des productions et des échanges de fruits et légumes au Cameroun, Cah. Agric. 10 (2001) 87-94.

[2] Westphal E., Embrechts J., Ferwerda J.D., Van Gils-Meeus H.A.E., Mutsaers H.J.W., Westphal-Stevels J.M.C., Cultures vivrières tropicales avec références spéciales au Cameroun, Pudoc, Wageningen, Pays-Bas, 1985, 514 p.

[3] Kuate J., Bella Manga, Hernandez S., Damesse F., Le secteur des fruits et légumes au Cameroun : importance, potentialités, contraintes et stratégies de développement, in: Proc. Atelier Concert. Polit. Agric. Opér. Économ., Douala, Cameroun, 27 février-2 mars 2001, Minagri, Yaoundé, Cameroun, 2001.

[4] Kouodiekong L., Diffusion des plants fruitiers sélectionnés dans la province du Centre: acquis et contraintes, Univ. Yaoundé I, DESS Ind. Semen., Rapp., Yaoundé, Cameroun, 1998.

[5] Nkana Ntéa B., Inventaire complet des pépinières fruitières et horticoles de la ville de Yaoundé, Univ. Dschang, FASA, Rapp., Dschang, Cameroun, 2002.

[6] Kengue J., Degrande A., Damesse F., Tchoundjeu Z., Rapport d'activité de recherche sur la production des plants des espèces fruitières et ornementales dans la zone urbaine et périurbaine de Yaoundé, Proj. SIUPA, IRAD-IITA-ICRAF, Yaoundé, Cameroun, 2003, $24 \mathrm{p}$.

[7] Gockowski J., Ndoumbé M., The adoption of intensive monocrop horticulture in southern Cameroon, Agric. Econ. 30 (2004) 195-202.

[8] Abeysekera S., Analysis approaches in participatory work involving ranks or scores, Univ. Reading, DFID, Stat. Serv. Cent., Theme pap. (revis.), UK, 2001, 18 p.

[9] Dongmo J.L., Le dynamisme bamiléké (Cameroun): I. La maîtrise de l'espace agraire, Univ. Yaoundé, Rapp., Cameroun, 1981, $424 \mathrm{p}$.

[10] Kuate J., Cercosporiose des agrumes causée par Phaeoramularia angolensis, Cah. Agric. 7 (1998) 121-129.

[11] Rey J.Y., Ducelier D., Njonga B., Maladies et ennemis des agrumes au Cameroun, MESRES-IRA, Yaoundé, Cameroun, 1985, $20 \mathrm{p}$.

[12] Bella-Manga, Dubois C., Kuate J., Mimbimi Ngbwa M., Rey J.Y., Sensibilité à Phaeoramularia angolensis de divers agrumes cultivés en zone forestière humide du Cameroun, Fruits 54 (3) (1999) 167-176.

[13] Degrande A., Schreckenberg K., Mbosso C., Anegbeh P., Okafor V., Kanmegne J., Farmer's fruit tree growing strategies in the humid forest zone of Cameroon and Nigeria, Agrofor. Syst. 67 (2006) 159-175.

[14] Assis A.J. de, Campos J.M. de S., Queiroz A.C. de, Valadares Filho S. de C., Euclydes R.F., Lana R. de P., Magalhaes A.L.R., Mendes Neto J., Mendonga S. de S., Citrus pulp in diets for milking cows. 2. Digestibility of nutrients in two periods of feces collection and rumen fluid $\mathrm{pH}$ and ammonia nitrogen, Rev. Bras. Zootec. 33 (1) (2004) 251-257.

[15] Porcionato M.A. de F., Berchielli T.T., Franco G.L., Andrade P. de, Silveira R.N. da, Soarez W.V.B., Digestibility, degradability and concentration of ruminal ammonia in bovines fed diet with citrus pulp in pellets, Rev. Bras. Zootec. 33 (1) (2004) 258-266. 


\section{Encuesta sobre los cultivos fruteros en las explotaciones familiares agrícolas en zona húmeda en Camerún.}

Resumen - Introducción. La falta de datos estadísticos fiables y exhaustivos referente a las explotaciones fruteras constituye un obstáculo para elaborar una estrategia pertinente de desarrollo de estos cultivos y evaluar su impacto. Se realizó una encuesta sobre los cultivos fruteros en tres emplazamientos (Bokito, Foréké y Yaoundé) en zona húmeda del Camerún. Material y métodos. Se caracterizaron los árboles frutales mediante análisis del perfil del productor y el lugar de estos cultivos en las actividades practicadas por las familias de los cultivadores agrícolas. Se estudiaron en 193 explotaciones familiares agrícolas las especies presentes, el número de plantones, el origen del material vegetal, la edad de los árboles, asî como las dificultades de producción. Resultados y discusión. Los jefes de explotación, de los cuales un $90 \%$ son hombres, tienen una media de 51 años y un nivel de educación relativamente bajo. La diversidad de las especies fruteras repertoriadas varía de acuerdo con los emplazamientos. La composición específica del vergel es asimismo variable, sin embargo cuatro especies principales (Dacryodes edulis, naranjo, mango y aguacate) constituyen el 78\% de las plantas destacadas. Este reparto corrobora las preferencias expresadas por los productores por estas especies fruteras. Los jóvenes árboles $(<10$ años), que indican una dinámica de replantación, constituyen $(15,21$ y 38) \% de los efectivos en Bokito, Foréké y Yaoundé respectivamente. No obstante, se observan y se discuten unas disparidades importantes intraespecíficas. En términos de contribución a la seguridad alimentaría del hogar, los árboles frutales, en relación con las especulaciones, ocupan el $1^{\circ}, 2^{\circ}$ y el $4^{\circ}$ puesto respectivamente en Bokito, Foréké y Yaoundé. Las dificultades de producción son del orden parasitario (enfermedades y plagas), agronómico (variedades, prácticas culturales, etc.) o socioeconómico (factor de producción, de propiedad, etc.). Conclusión. Nuestro trabajo permitió obtener unos datos importantes sobre los árboles frutales cultivados en zona húmeda de Camerún. Las implicaciones de los principales resultados se discuten en la perspectiva de mejorar estas producciones en la calidad, cantidad y en la duración. Camerún / árboles frutales / encuestas sobre explotaciones / zonas
periurbanas / agentes nocivos 